\title{
Assessment of Acid Base and Electrolyte Status in Patients with Chronic Kidney Disease
}

\author{
Mahrukh Hameed, Ph.D', Syed Mudassar, Ph.D', Mosin S. Khan, Ph.D', Nisar Ahmad Wani, Ph.D² \\ 'Department of Clinical Biochemistry, Sher-I-Kashmir Institute of Medical Sciences, Srinagar \\ ${ }^{2}$ Deparment of Immunology, Sher-I-Kashmir Institute of Medical Sciences, Srinagar
}

\section{A B S T R A C T}

\begin{abstract}
Background: Blood gas measurements are being used to evaluate oxygenation and acid/base status. They are typically ordered if a patient has worsening symptoms of an acid/base imbalance, difficulty in breathing or shortness of breath. Blood gas analysis has been a cornerstone in the management of acutely ill patients with presumed acid/base and electrolyte imbalance.

Objective: The aim of this study was to study the blood gases and electrolyte status in patients with chronic kidney disorder.

Methods: A prospective study was conducted in the department of Clinical Biochemistry, Sher-I Kashmir Institute of Medical Sciences Srinagar. A total of 171 patients were included in the study of which 91 were males and 80 were females. The age of the patients ranged between $4-80$. These patients were admitted in the Nephrology ward of SKIMS. Out of these 171 patients included in the study 99 had CKD, 42 had ARF, 11 had metabolic acidosis, 6 had nephritic syndrome, 2 had lupus nephritis and 11 had complications like dysuria, HTN, glomerular diseases etc. The medical history of the patients with CKD was recorded and Samples were obtained for blood gas analysis. Venous samples were obtained for VBG analysis and arterial samples were obtained for ABG analysis. These samples were analysed for determining the blood gas status. Hemoglobin levels and kidney function test were performed manually. Hemoglobin was estimated by cyanmet-hemoglobin method. Urea was estimated by Diacetyl monoxime (DAM) method. Creatinine was estimated by Jaffe's reaction.

Results: CKD patients showed acidosis, hypocapnia and hypoxia. Among electrolytes almost all the patients with CKD had hyponatremia and increased anion gap.

Conclusion: It was concluded from the observation that male predominance was seen in chronic kidney disease. Blood gas parameters including $\mathrm{pH}, \mathrm{PCO} 2, \mathrm{PO} 2, \mathrm{HCO} 3$ were found to be deranged in most of the patients with $\mathrm{CKD}$. Among electrolytes sodium was found to be mostly deranged in patients with CKD and Anemia was the most common finding in patients with this disorder. JMS 2013; 16(2):86-89

Keywords: Blood gas analysis, CKD, ARF, Electrolytes, Urea, Creatine, ESRD
\end{abstract}

\section{INTRODUCTION}

Blood gas analysis is used to measure the $\mathrm{pH}$ and the partial pressures of oxygen and carbon dioxide in the blood. The investigation is relatively easy to perform and yields information that can guide the management of acute and chronic illnesses. This information indicates a patient's acid- base balance, the effectiveness of their gas exchange and the state of their ventilatory control that is blood gas analysis is often performed in to assess acid-base disturbances, and to diagnose and quantify respiratory insufficiency. Blood gas analysis is a means of determining the amount of oxygen or carbon dioxide being carried in the

\section{Correspondence}

Dr. Syed Mudassar Andrabi, Ph.D

Addl. Professor \& Head

Department of Clinical Biochemistry

Sher-I-Kashmir Institute of Medical Sciences, Srinagar

email: syed.mudassar@skims.in blood and in some cases of the discovering the identity of toxic gas, such as carbon monoxide that may be present. Also, the determination can be made as to whether the blood is too acidic or too alkaline, which may help the physician in his diagnosis. ${ }^{1}$ An arterial blood gas analysis is performed on blood from arteries. An ABG analysis evaluates how effectively the lungs are delivering oxygen to the blood and how efficiently they are eliminating carbon dioxide from it. The test also indicates how well the lungs and kidney are interacting to maintain normal blood $\mathrm{pH}$ (acid base balance). Blood gas studies are usually done to assess respiratory disease and other conditions that may affect the lungs and to manage patients receiving oxygen therapy (respiratory therapy). ${ }^{2}$ In addition, the acid-base component of the test provides information on kidney function. Blood gas analysis measures the partial pressures of oxygen 
and carbon dioxide in the blood, as well as oxygen content, oxygen saturation, bicarbonate content and blood $\mathrm{pH}^{3}$ Electrolytes are present in the human body and the balance of the electrolytes in our bodies is essential for normal function of our cells and our organs. They help to regulate myocardial and neurological functions, fluid balance, oxygen delivery, acid base balance and much more. Some of the most important electrolytes in blood are sodium, potassium and chloride. ${ }^{4}$ The levels of each electrolyte is kept within normal range by several mechanisms. Any change in their level leads to electrolyte imbalance, which if severe can lead to life threatening consequences.

Chronic renal failure (CRF) or more appropriately chronic kidney disease (CKD) refers to a decline in the glomerular filtration rate (GFR) caused by a variety of diseases such as diabetes, glomerulonephritis and polycystic kidney disease. Patients with CKD have a high prevalence of hypertension. CKD may be categorized as mild (GFR of $60-89 \mathrm{ml} / \mathrm{min}$ ), moderate (GFR of $30-59 \mathrm{ml} / \mathrm{min}$ ), severe (GFR of 15$29 \mathrm{ml} / \mathrm{min}$ ) or end stage renal disease (ESRD). Some patients with CKD eventually receive kidney transplantation before (a few cases) or after (most recipients) the initiation of hemodialysis or peritoneal dialysis. 5 The present study was conducted to study the blood gases and electrolyte status in patients with chronic kidney disease (CKD).

\section{METHODS}

This was a hospital based study conducted in the department of Clinical Biochemistry, Sheri Kashmir Institute of Medical Sciences Srinagar. The patients involved in the study were admitted in the Nephrology ward of SKIMS, Srinagar A total of 171 patients were included in this study of which 91 were males and 80 were females. The age of the patients ranged between 4 years 80 years. Clinical details and history of said patients was taken followed by assessment of hemoglobin levels and kidney function test. Also heparinised blood samples were obtained for blood gas analysis. Venous samples were obtained for VBG analysis and arterial samples were obtained for ABG analysis. Theses samples were analyzed for determining the blood gas status. The sampling parameters included in the study were $\mathrm{pH}, \mathrm{PCO}^{2}, \mathrm{PO}^{2}, \mathrm{HCO}^{3}, \mathrm{Na}+, \mathrm{K}+, \mathrm{Cl}-$ and Anion gap.
Hemoglobin was estimated by cyanmethemoglobin method. Urea was estimated by Diacetyl monoxime (DAM) method and Creatinine was estimated by Jaffe's reaction.

Statistical analysis was done by using S.D and probability $p$ values $(\mathrm{p}<0.05)$ were considered statistically significant.

\section{RESULTS}

171 patients including 91 males and 80 females were included in this study. Maximum number of patients were in the age group of 41 years 60 years (Table 1). Male : Female ratio was found to be 1.13:1.

Table 1: Age and sex distribution in patients with kidney diseases

\begin{tabular}{|l|c|c|c|}
\hline \multirow{2}{*}{ Age Group } & Male & Female & Total \\
\cline { 2 - 4 } & $\mathrm{n}(\%)$ & $\mathrm{n}(\%)$ & $\mathrm{n}(\%)$ \\
\hline $0-20$ & $11(12)$ & $6(8)$ & $17(10)$ \\
\hline $21-40$ & $22(24)$ & $29(36)$ & $51(30)$ \\
\hline $41-60$ & $38(42)$ & $21(26)$ & $59(35)$ \\
\hline $61-80$ & $20(22)$ & $24(30)$ & $44(26)$ \\
\hline Total & $91(53)$ & $80(47)$ & $171(100)$ \\
\hline
\end{tabular}

Out of 171 patients 99 had CKD (57.89\%), 42 had ARF (24.56\%), 11 had metabolic acidosis (6.43\%), 6 had nephritic syndrome (3.50\%), 2 had lupus nephritis (1.16\%), 11 had other diseases (which include HTN, RTA, dysuria, glomerular diseases) (6.43\%) (Table 2).

Table 2: Disease distribution of patients

\begin{tabular}{|l|c|}
\hline \multicolumn{1}{|c|}{ Diseases } & \multicolumn{1}{|c|}{ n (\%) } \\
\hline CKD & $99(57.89 \%)$ \\
\hline ARF & $42(24.56 \%)$ \\
\hline Metabolic acidosis & $11(6.43 \%)$ \\
\hline Nephritic syndrome & $6(3.50 \%)$ \\
\hline Lupus nephritis & $2(1.16 \%)$ \\
\hline $\begin{array}{l}\text { Other diseases } \\
\text { RTA, dysuria, glomerular } \\
\text { diseases). }\end{array}$ & $11(6.43 \%)$ \\
\hline
\end{tabular}

99 patients had CKD (47 males, 52 females). Maximum patients admitted with the diagnosis of CKD were in the age group of 41-60 yrs with a sex ratio (Male : Female ratio $=0.90\}$ (Table 3 ). 
Table 3: Age and sex distribution in patients with CKD

\begin{tabular}{|c|c|c|c|}
\hline Age group & Males & Females & Total \\
\hline & $\mathrm{n}(\%)$ & $\mathrm{n}(\%)$ & $\mathrm{n}(\%)$ \\
\hline $0-20$ & $5(10)$ & $3(6)$ & $8(8)$ \\
\hline $21-40$ & $13(28)$ & $17(33)$ & $30(30)$ \\
\hline $41-60$ & $22(47)$ & $\mathrm{I} 5(29)$ & $37(37)$ \\
\hline $61-80$ & $7(15)$ & $17(33)$ & $24(25)$ \\
\hline Total & $47(47)$ & $52(53)$ & $99(100)$ \\
\hline
\end{tabular}

Acidosis was seen in $62(63 \%)$ patients with CKD, out of which $15 \%$ had mild acidosis and $14 \%$ had severe acidosis. Also maximum number of patients with CKD had significant bicarbonate deficit i.e. $78(80 \%)$ while $13(13 \%)$ had normal bicarbonate levels (Table 4). 62 (65\%) patients had hypocapnia, $30(31 \%)$ patients had normal PCO2 levels, 4(4\%) had high PC02 levels.42 (93.33\%) patients with CKD had hypoxia out of which $29 \%$ had mild hypoxia, $18 \%$ had moderate hypoxia and $47 \%$ had severe hypoxia.

Table 4: Blood gases status in patients with CKD

\begin{tabular}{|c|c|c|}
\hline Parameters & $\begin{array}{c}\text { Clinical } \\
\text { Conditions }\end{array}$ & n $(\%)$ \\
\hline \multirow{5}{*}{$\begin{array}{l}\mathrm{pH} \\
\mathrm{n}=99\end{array}$} & Mild acidosis & $15(15)$ \\
\hline & $\begin{array}{l}\text { Moderate } \\
\text { acidosis }\end{array}$ & $33(33)$ \\
\hline & Severe acidosis & $14(14)$ \\
\hline & Normal & $34(34)$ \\
\hline & Alkalosis & $3(3)$ \\
\hline \multirow{6}{*}{$\begin{array}{l}\mathrm{PO} 2 \\
n=45\end{array}$} & Mild hypoxia & $13(29)$ \\
\hline & $\begin{array}{l}\text { Moderate } \\
\text { hypoxia }\end{array}$ & $8(18)$ \\
\hline & Severe hypoxia & $21(47)$ \\
\hline & Normal & $3(7)$ \\
\hline & Hyperoxia & Nil \\
\hline & Not assigned & $54(55)$ \\
\hline \multirow{6}{*}{$\begin{array}{l}\mathrm{PCO} 2 \\
\mathrm{n}=96\end{array}$} & Mild hypocapnia & $28(30)$ \\
\hline & $\begin{array}{l}\text { Moderate } \\
\text { hypocapnia }\end{array}$ & $28(30)$ \\
\hline & $\begin{array}{l}\text { Severe } \\
\text { hypocapnia }\end{array}$ & $6(6)$ \\
\hline & Normal & $30(31)$ \\
\hline & $\begin{array}{l}\text { Mild } \\
\text { hypercapnia }\end{array}$ & $4(4)$ \\
\hline & Not Assigned & $3(3)$ \\
\hline \multirow{6}{*}{$\begin{array}{l}\mathrm{HC} \mathrm{O} 3 \\
\mathrm{n}=97\end{array}$} & Mild & $23(24)$ \\
\hline & $\begin{array}{l}\text { Moderate } \\
\text { deficit }\end{array}$ & $13(13)$ \\
\hline & Severe & $42(43)$ \\
\hline & Normal & $13(13)$ \\
\hline & Mild & $6(6)$ \\
\hline & Kot Assigned & $2(2)$ \\
\hline
\end{tabular}

Table 5: Electrolyte status in patients with CKD

\begin{tabular}{|c|c|c|}
\hline Parameters & $\begin{array}{c}\text { Clinical } \\
\text { Conditions }\end{array}$ & n (\%) \\
\hline \multirow{6}{*}{$\begin{array}{l}\mathrm{Na}^{+} \\
\mathrm{n}=99\end{array}$} & $\begin{array}{l}\text { Mild } \\
\text { hyponatremia }\end{array}$ & $28(29)$ \\
\hline & $\begin{array}{l}\text { Moderate } \\
\text { hyponatremia }\end{array}$ & $40(41)$ \\
\hline & $\begin{array}{l}\text { Severe } \\
\text { hyponatremia }\end{array}$ & $10(10)$ \\
\hline & Normal & $18(18)$ \\
\hline & $\begin{array}{l}\text { Mild } \\
\text { hyponatremia }\end{array}$ & $2(2)$ \\
\hline & Not assigned & $1(1)$ \\
\hline \multirow{5}{*}{$\begin{array}{l}\mathrm{K}^{+} \\
\mathrm{n}=99\end{array}$} & $\begin{array}{l}\text { Mild } \\
\text { hypokalemia }\end{array}$ & $16(16)$ \\
\hline & $\begin{array}{l}\text { Moderate } \\
\text { hypokalemia }\end{array}$ & $5(5)$ \\
\hline & $\begin{array}{l}\text { Severe } \\
\text { hypokalemia }\end{array}$ & $7(7)$ \\
\hline & Normal & $53(54)$ \\
\hline & $\begin{array}{l}\text { Mild } \\
\text { hyperkalemia }\end{array}$ & $18(18)$ \\
\hline \multirow{4}{*}{$\begin{array}{l}\mathrm{Cl}^{-} \\
\mathrm{n}=61\end{array}$} & Hypochloremia & $36(59)$ \\
\hline & Normal & $22(36)$ \\
\hline & Hyperchloremia & $3(5)$ \\
\hline & Not Assigned & $38(38)$ \\
\hline \multirow{4}{*}{$\begin{array}{l}\text { Anion gap } \mathrm{n} \\
=60\end{array}$} & $\begin{array}{l}\text { Increased anion } \\
\text { gap }\end{array}$ & $51(85)$ \\
\hline & Normal & $6(10)$ \\
\hline & $\begin{array}{l}\text { Decreased } \\
\text { anion gap }\end{array}$ & $3(5)$ \\
\hline & Not Assigned & $39(40)$ \\
\hline
\end{tabular}

Almost all the electrolytes were deranged in patients with CKD but Hyponatrenmia was highly significant than hyperkalemia and hyperchloremia. $78(80 \%)$ patients with CKD had hyponatrenmia and only $18(18 \%)$ patients had normal sodium levels. 28(28\%) patients with CKD had hypokalemia, $8(18 \%)$ of patients had hyperkalemia and $53(54 \%)$ of patients had normal potassium levels. Hyperchloremia was seen in $36(59 \%)$ patients with CKD while 22(36\%) had normal chloride levels and 3(5\%) had hypochloremia. 51(85\%) patients had elevated anion gap and 6(10\%) had normal anion gap (Table 5).

Anemia was the most common finding in patients with this disorder. Mild anemia was reported in $7(12 \%)$ of patients. Moderate anemia was found in $39(67 \%)$ of patients. $10(17 \%)$ of patients had severe anemia and $2(3 \%)$ had normal hemoglobin levels (Table 6). 
Table 6: Hemoglobin results in patients with CKD

\begin{tabular}{|l|c|}
\hline \multicolumn{1}{|c|}{ Hemoglobin (g/d) } & n (\%) \\
\hline Mild anemia $(\mathrm{n}=58)$ & $7(12)$ \\
\hline Moderate anemia $(\mathrm{n}=58)$ & $39(67)$ \\
\hline Severe anemia $(\mathrm{n}=58)$ & $10(17)$ \\
\hline Normal $(\mathrm{n}=58)$ & $2(3)$ \\
\hline Not assigned & $41(41)$ \\
\hline
\end{tabular}

Table 7: Lab parameters in patients with CKD

\begin{tabular}{|l|c|c|}
\hline $\begin{array}{c}\text { Laboratory } \\
\text { parameters }\end{array}$ & Mean & Range \\
\hline $\mathrm{Hb}$ & $8.60 \mathrm{~g} / \mathrm{dl}$ & $(6.2-9.9)$ \\
\hline Urea & $175.57 \mathrm{~g} / \mathrm{dl}$ & $(101-309)$ \\
\hline Creatinine & $8.44 \mathrm{~g} / \mathrm{dl}$ & $(3.07-$ \\
& & $17.73)$ \\
\hline
\end{tabular}

\section{DISCUSSION}

An ABG analysis evaluates how effectively the lungs are delivering oxygen to the blood and how efficiently they are eliminating carbon dioxide from it. An arterial blood gas (ABG) test measures the acidity $\mathrm{pH}$ and the levels of oxygen and carbondioxide in the blood from an artery. They are typically ordered if a patient has worsening symptoms of an acid /base imbalance, difficulty in breathing or shortness of breath. Chronic kidney disease is the most prevalent disease in kidney disorders. Anemia is the most common complication of this disease Anemia was reported in $56(96 \%)$ out of 58 patients with CKD. It has multiple causes, the most important of which is decreased production of erythropoietin by the kidney. Its prevalence and severity increases with deteriorating renal function. This is in agreement with the findings of Kammerer et al, 2002. ${ }^{6}$ In CKD increased levels of urea and creatinine are attributed to rapiddecline in renal filtration function. Same was also reported by a group of scientists who found that in CKD stage 4-5 hyperkalemia emerges, in addition to that sodium, chloride and bicarbonate levels also change. ${ }^{7}$
In most CKD patients electrolyte levels are deranged. Hyponatremia, Hyperkalemia is often associated with CKD. ${ }^{7}$ Also Phosphorous and calcium levels are altered and Metabolic acodosis is associated with $\mathrm{CKD}^{7}$ In the present study it was concluded that male predominance was seen in kidney disorders that is number of male patients was more than female patients and among the kidney disorders the most prevalent disease was CKD followed by ARF, metabolic acidosis, nephritic syndrome, lupus nephritis, glomerular diseases etc. We conclude that hyponatremia is highly significant than hyperkalemia and hyperchloremia. Despite the disease breathlessness, decreased urinary output, swelling facial puffiness were the mostly commonly observed symptoms in patients.

\section{REFERENCES}

1. Thomson. Mosby's Clinical Nursing. $4^{\text {th }}$ edition.$S t$. Louis Mosby. 1997.

2. Gold, W.G. Pulmonary functioning testing. Text book of respiratory medicine. 2005, $3^{\text {rd }}$ edition Philadelphia: Saunders Elsevier, Chapter-24.

3. Burnett, R.W., Ehremey, S. S., Moran, R.F., and Vankessel, A. L. Blood gas and $\mathrm{pH}$ analysis and related measurements. National committee for clinical laboratory standards. 2001.

4. Joan, E.P. Electrolytes: Clinical chemistry, Principle procedures and co-relations. $5^{\text {th }}$ edition. $2005315-341$.

5. Malik, H, Sirwal, L.A., Reshi, A.R., Tanvir, M., and Altaf, M. Patterns of acute renal failure in Kashmir Valley. Indian Journal of Nephrology.1992 2(1): 12441248.

6. Kammerer J.etal: Anaemia in CKD: Prevalence, diagnosis and treatment. Nephrology Nursing Journal, 2002 29:371-374.

7. Alcazar, A.R. Electrolyte and acid base disorders in CKD. Nephrologia. 2008 3:87-93. 